\title{
Optimization of drum drying parameters for gac powder
}

\author{
Pornthip Suriyajunhom ${ }^{1}$, and Maradee Phongpipatpong ${ }^{1}$ \\ ${ }^{1}$ Food Engineering Department, Faculty of Engineering, King Mongkut's Institute of Technology Ladkrabang, Bangkok, Thailand
}

\begin{abstract}
Gac (Momordica cochinchinensis Spreng.) is a tropical fruit which contains a rich nutrient source, especially lycopene. However, fresh gac fruit can spoil rapidly due to its high moisture content. Drum drying is a process to remove moisture from food in order to preserve nutrients and extend shelf life. In this study, gac fruit powder was produced by using drum drying technique. The present research was aimed to determine the optimum drum drying condition for gac powder. Response Surface Methodology was employed with three processing variables, including drum surface drying temperature $\left(115,125,135^{\circ} \mathrm{C}\right)$ maltodextrin content $(100,150,200 \%)$ and gum arabic content $(10,20,30 \%)$. The response variables were moisture content, solubility, hygroscopicity, total phenolic content and lycopene content of gac fruit powder. Regression analysis was then performed to obtain the mathematical relation between the processing variables and the responses in the form of second-order polynomial equations.. The results showed that optimum conditions for drum drying of gac fruit was at $135^{\circ} \mathrm{C}$ of drum surface dry ing temperature, $138 \%$ of added maltodextrin and $10 \%$ of added gum arabic, which provided the highest amount of total phenolic and ly copene content.
\end{abstract}

\section{Introduction}

Gac is a tropical fruit which classified in the cucurbitaceae family. It grows in many countries in Asia including China, Malaysia, Vietnam and Thailand. This plant can grow fast and has a low price, but it is a good source of nutrients such as vitamin $\mathrm{E}$, fatty acid, phenolic compound, carotenoid - Lycopene and beta-carotene $[1,2]$. However, fresh gac fruit has a short shelf life due to its high moisture content that susceptible to deterioration. Thus, food processing can be applied in order to prevent spoilage, develop and add value to the product. Drum Drying is one of popular processing technique to convert food into a dried flake or powder which can help to keep nutrition and to prolong shelf-life of fruit product. The advantage of drum drying is that the simpler structure of the dryer, less operating costs, less drying time, higher drying capacity, and can be applied to wider ranges of liquid food or viscous food [3]. A typical drum dryer may have either a single drum with smaller applicator rolls or double drums. In this dryer, pureed food is spread uniformly over the surface of a heated drum. While the drum rotates, drying takes place and dried product is scraped off as flake from the drum using a knife system. The product can further grind into powder form. $[3,4]$.

Several studies have reported the problem of the development of stickiness and caking during fruit drying due to the presence of low molecular weight sugars and acids which have low glass transition temperature, results in lower product yield, operation shut-downs, equipment wear, difficulties in material storage and handling. This causes a considerable economic loss and consumers' discrimination [5]. Caking and stickiness are enhanced by numerous factors such as glass transition temperature $(\mathrm{Tg})$ and hygroscopicity of the food materials, and environmental temperature and relative humidity etc. Therefore carrier agents e.g. maltodextrins, gum arabic, waxy starch, and microcrystalline cellulose are usually added into the feed prior to drying step, influence the properties and stability of the powder. Maltodextrin is the most common drying aids which helps increase in $\mathrm{Tg}$ of the food product. The addition of maltodextrin can be applied to reduce stickiness of the powder during drying especially for sugar rich foods [6]. Gum arabic is mixture of polysaccharides and glycoproteins, it is used primarily in the food industry as a stabilizer and emulsifier to enhance the favour and stability of food product. However, the addition level of carrier agents is important to obtain the desired food powder characteristics. [7]

The optimization of processing parameters is essential in food engineering and product development. Response surface methodology (RSM) has been successfully applied to optimize food processing operations including drying. This method requires identifying and fitting experimental data and appropriate response surface model with the use of statistical experimental design, regression modeling techniques, and optimization methods.[8] The most common forms of response variables and design variables are low-order polynomials (first or second-order).

Since drum drying is an energy-efficient and low production cost process, it is interesting to apply this technique for gac fruit. Therefore, this research is aimed to study drumdrying process for gac powder production and

\footnotetext{
* Corresponding author: maradee.ph@kmitl.ac.th
} 
to optimize the process conditions to obtain the desirable characteristics of drum-dried gac fruit powder.

\section{Materials and methods}

\subsection{Sample Preparation}

Fresh gac fruits were collected from plantation area in Kanchanaburi province after approx. 150 days after flowering. Only mesocarp and endocarp were manually separated from the fruit, blended and pasteurized at $72^{\circ} \mathrm{C}$ for $15 \mathrm{sec}$. before packed into polyethylene bags and kept in a freezer at $-180 \mathrm{C}$ until be analysed and processed.

\subsection{Drum Drying Operation}

For drum drying experiments, the frozen gac pureed samples were thawed overnight at room temperature then mixed with Maltodextrin DE-10 and gum arabic at different amounts based on experiment design. A doubledrum dryer was used for drying trials. Steam is used as heating medium and fed into the drum. Drum surface temperature can be adjusted by controlling steam pressure (at 10, 20, $30 \mathrm{psig}$ ). The dried gac samples were scraped out from the drums and kept in aluminum foil bag until analysis.

\subsection{Experimental design}

Response surface methodology was used as an optimization approach. Experimental data of gac fruits drying tests carried out based on Box-Behken design as shown in Table 1. The effect of drum surface drying temperature, maltodextrin concentration and gum Arabic concentration, selected as independent variables, on physicochemical properties of gac powder including mois ture content, solubility hygroscopicity, total phenolic content and lycopene content was described by polynomial models. The experiment results were analysed and expressed in the form of Eq. (1). Optimization procedure was finally performed using graphical analysis with superimposed contour plot.

$$
Y=\beta_{0}+\sum_{i=1}^{n} \beta_{i} X_{i}+\sum_{i=1}^{n} \beta_{i i} X_{i}^{2}+\sum_{i=1}^{n-1} \sum_{j=i+1}^{n} \beta_{i j} X_{i} X_{j}
$$

Where $\mathrm{Y}=$ Physicochemical properties of gac fruit powder

$\mathrm{X}_{\mathrm{i}}=$ Variable such as drying temperature $\left({ }^{\circ} \mathrm{C}\right)$ maltodextrin $(\%)$ and gum arabic $(\%)$

$\beta_{0}=$ Regression coefficient at Y-intercept

$\beta_{\mathrm{i}}=$ Regression coefficient in term of linear, quadratic and interaction

Table 1 Independent variables and their levels in the BoxBehnken design.

\begin{tabular}{ccccc}
\hline \multirow{2}{*}{ Independent variables } & \multirow{2}{*}{ symbol } & \multicolumn{3}{c}{ Coded values } \\
\cline { 3 - 5 } & & -1 & 0 & +1 \\
\hline Dry ing temperature $\left({ }^{\circ} \mathrm{C}\right)$ & $\mathrm{X}_{1}$ & 115 & 125 & 135 \\
Maltodextrin content $(\%)$ & $\mathrm{X}_{2}$ & 100 & 150 & 200 \\
Gum Arabic content $(\%)$ & $\mathrm{X}_{3}$ & 10 & 20 & 30 \\
\hline
\end{tabular}

\subsection{Physicochemical Properties Analysis}

\subsubsection{Moisture content}

The gac powder sample was dried in the oven at $105^{\circ} \mathrm{C}$ until the weight of sample remained unchanged. The results were computed as shown in Eq. (2).

$$
\text { Moisture content }(\%)=\frac{W_{1}-W_{2}}{W_{1}} \times 100
$$

When $\mathrm{W}_{1}=$ initial sample weight before oven drying $(\mathrm{g})$ $\mathrm{W}_{2}=$ dried sample weight after oven drying. (g)

\subsubsection{Solubility}

25 gms of dried gac powder was dissolved in $30 \mathrm{ml}$ of water for $10 \mathrm{~min}$. and centrifuged at $3,000 \mathrm{rpm}$ for 15 mins. Supernatant liquid was poured and dried in hot air oven at $105^{\circ} \mathrm{C}$ until the weight remained unchanged. The results were computed as shown in Eq. (3). [9]

$$
\text { Solubility }(\%)=\frac{\text { Weight of solids in the dried supernatant }}{\text { Weight of initial solids sample }} \times 100
$$

\subsubsection{Hygroscopicity}

Hygroscopicity were determined according from Bhusari et al (2014) by placing $1 \mathrm{~g}$ of dried gac powder in saturated solution of sodium chloride for 14 days. Hygroscopicity was then calculated based on Eq. (4) and expressed in $g_{\text {moisture }} \mathrm{g}^{-1}$ dry solid. [10]

$$
\text { Hygroscopicity }\left(\frac{g_{\text {moisture }}}{100 g_{\text {dry solid }}}\right)=\frac{\frac{\Delta m}{\left(m_{i}+m\right)}}{\frac{\Delta m}{m}+1}
$$

When $\quad m_{i}=$ The free water contents of the powder before placing into the saturated environment. (g) $m=$ The initial mass of powder. (g) $\Delta m=$ The increase in the weight of powder after equilibrium. (g)

\subsubsection{Total phenolic content [11]}

Total phenolic content was determined using the FolinCiocalteau reagent method. The absorbance was measured using UV-vis spectrophotometer at $765 \mathrm{~nm}$ wave length. Total phenolic contents of gac powder were calculated using a standard curve of Gallic acid and report as mg GAE $\mathrm{g} / 100 \mathrm{~mL}$

\subsubsection{Lycopene content}

Lycopene content were determined according to the Kimura method [12]. The absorbance was measured with UV-vis spectrophotometer at different wave lengths including 453, 505, 645 and $663 \mathrm{~nm}$. Lycopene content in gac juice powder were calculated based on Eq.5 and reported unit in $(\mathrm{mg} / 100 \mathrm{~g})$.

$$
\begin{aligned}
\text { Lycopene content }=- & 0.0458 \mathrm{~A}_{663}+0.204 \mathrm{~A}_{645}+.372 \mathrm{~A}_{505} \\
& -0.0806 \mathrm{~A}_{453}
\end{aligned}
$$

When A663, A645, A505 and A453 is absorbance at 663, 645,505 and $453 \mathrm{~nm}$ respectively 


\section{Result and discussion}

The relationships between the response variables and three independent variables were investigated and correlated using a $2^{\text {nd }}$ order polynomial equation, Eq. 1. ANOVA evaluations of these models are presented in Table 2.

\subsection{Moisture content}

In this study, the experiments show that the increase in drying temperature, maltodextrin content and gum arabic content result in a negative effect on gac powder mois ture content. The most significant factor on product moisture was drying temperature $(p<0.1)$. Similar results were also observed by Galaz et. al. [4], they reported that the effect of steam pressure or drying temperature on product moisture content is highest, followed by drum speed. Higher temperature reduces feed viscosity, reduces the entrainment flow of liquid on drum surface and thereby reduces dried product moisture. The minimum moisture content of gac powder was $1.5 \%$ when drying at $135^{\circ} \mathrm{C}$ of drum surface temperature, $200 \%$ of maltodextrin addition and $30 \%$ of gum arabic addition to the gac fruit pureed before fed to the drum dryer. The contour plot of drumdried gac powder is presented in Fig. 1.

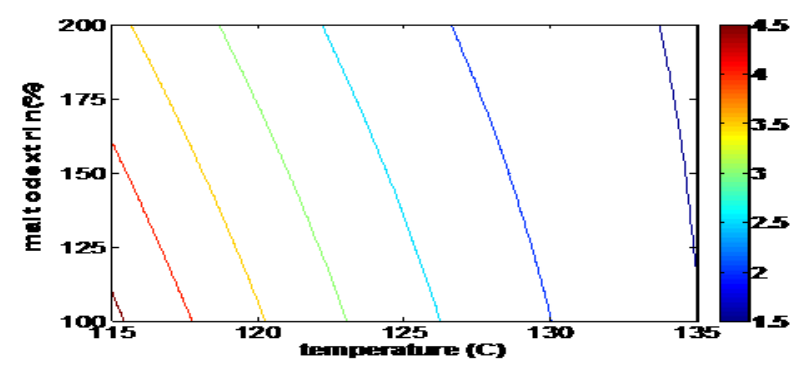

Fig.1 .Moisture content of drum-dried gac powder affected by drying température and maltodextrin content at $10 \%$. gum arabic

\subsection{Solubility}

Solubility of drum-dried gac powder was increased with drying temperature and maltodextrin content. While the addition of gum arabic had little effect on product solubility. Increasing the concentration of maltodextrin or gum arabic result in the decrease intermolecular forces by interacting with the functional groups of the polysaccharide, providing an increase in solubility. The contourplots of product solubility is present in Fig. 2 and it shows that the highest solubility $(76 \%)$ of drum-dried gac powder was at the high temperature and high amount of maltodextrin addition. Higher drying temperature increases the volume of gac powder and make it more porous. This cause product powder can dissolve faster. It was also observed that maltodextrin and gum arabic are a good dis solvable substance. [11].

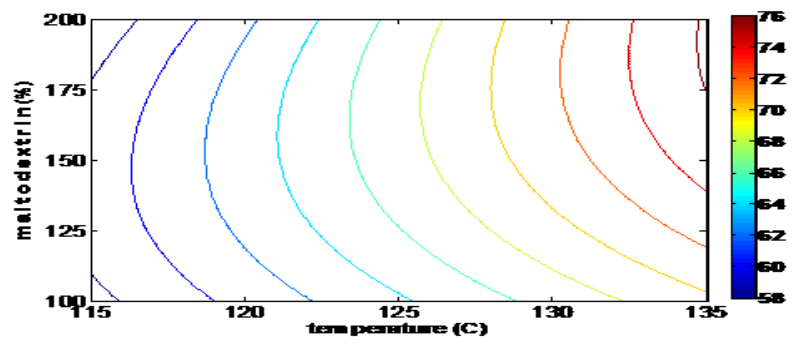

Fig. 2. Solubility of gac powder as affected by drying temperature and maltodextrin content at $10 \%$ gum arabic

\subsection{Hygroscopicity}

In this study it was found that the interaction of maltodextrin and gum arabic content was the most significant positive effect on hygroscopicity of gac fruit powder $(p<0.01)$. While drying temperature has little effect on hygroscopicity. The highest value of hygroscopicity of gac fruit powder also occurred at high drying temperature and higher amount of carrier agents (maltodextrin and gum Arabic) as shown in Fig 3

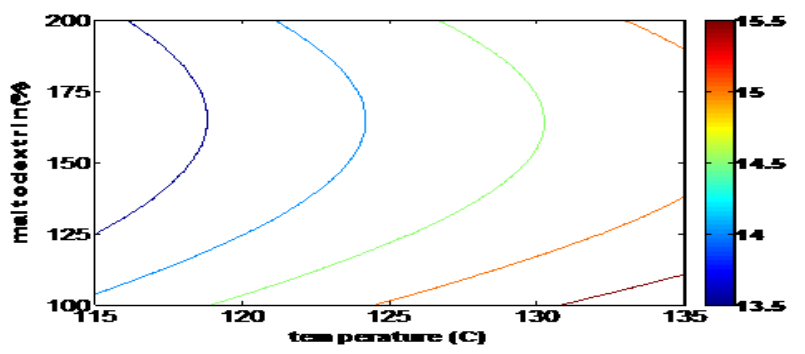

Fig. 3. Hygroscopicity of gac powder as affected by drying temperature and maltodextrin content at $10 \%$ of gum Arabic

Table 2 Regression coefficients of the second-order polynomial response models.

\begin{tabular}{|c|c|c|c|c|c|c|}
\hline Variables & $\begin{array}{l}\text { Regression } \\
\text { coefficient }\end{array}$ & $\begin{array}{c}\text { Moisture } \\
\text { content }(\%)\end{array}$ & Solubility (\%) & $\begin{array}{l}\text { Hy groscopicity } \\
\left.\text { (gwater } / 100 g_{\text {powder }}\right)\end{array}$ & $\begin{array}{c}\text { Total phenolic } \\
\text { content }\end{array}$ & $\begin{array}{l}\text { Lycopene } \\
\text { content }\end{array}$ \\
\hline intercept & $\beta_{0}$ & 87.84399 & -36.4979 & 0.740489 & -64.6843 & -0.09806 \\
\hline $\mathrm{x}_{1}$ & $\beta_{1}$ & $-1.13828 *$ & 0.989454 & 0.288347 & 0.91774 & 0.001247 \\
\hline $\mathrm{x}_{2}$ & $\beta_{2}$ & -0.06309 & -0.22095 & $0.050087^{*}$ & 0.025576 & -0.00088 \\
\hline $\mathrm{x}_{3}$ & $\beta_{3}$ & -0.18276 & 1.312556 & 0.208455 & 0.508405 & 0.01567 \\
\hline $\mathrm{x}_{1} \cdot \mathrm{x}_{1}$ & $\beta_{11}$ & 0.003685 & -0.00257 & 0.435144 & -0.00249 & $1.21 \mathrm{E}-05$ \\
\hline $\mathrm{x}_{2} \cdot \mathrm{x}_{2}$ & $\beta_{22}$ & $1.17 \mathrm{E}-06$ & $-0.00079 * *$ & $0.002973 * * *$ & $9.41 \mathrm{E}-05$ & $3.44 \mathrm{E}-06$ \\
\hline$x_{3} \cdot x_{3}$ & $\beta_{33}$ & -0.00163 & 0.007121 & 0.060509 & -0.00024 & $2.87 \mathrm{E}-05$ \\
\hline $\mathrm{x}_{1} \cdot \mathrm{x}_{2}$ & $\beta_{12}$ & 0.00046 & $0.003851 * *$ & 0.855142 & -0.00061 & $-2.8 \mathrm{E}-06$ \\
\hline $\mathrm{x}_{2} \cdot \mathrm{x}_{3}$ & $\beta_{13}$ & 0.00024 & $0.00052 *$ & 0.026412 & 0.000131 & $-2.1 \mathrm{E}-06$ \\
\hline $\mathrm{x}_{1} \cdot \mathrm{x}_{3}$ & $\beta_{23}$ & 0.001667 & -0.01266 & $0.214111 * *$ & -0.0042 & -0.00013 \\
\hline \multicolumn{2}{|c|}{ R Square $\left(\mathrm{R}^{2}\right)$} & 0.9476 & 0.9883 & 0.9794 & 0.8207 & 0.6381 \\
\hline \multicolumn{2}{|c|}{ Standard Error (S.E.) } & 0.3573 & 1.0032 & 0.2064 & 0.9613 & 0.0194 \\
\hline
\end{tabular}

Note $*$ Significant at $\mathrm{p}<0.1, * *$ Significant at $\mathrm{p}<0.05$ and $* * *$ Significant at $\mathrm{p}<0.01$ 


\subsection{Total phenolic content}

Total phenolic content of gac powder is shown in Fig 4. The study shows that the maximum total phenolic content of gac powder was $8.5 \mathrm{mg} \mathrm{GAE} \mathrm{g/100} \mathrm{mL} \mathrm{and} \mathrm{occured} \mathrm{at}$ high drying temperature $\left(135^{\circ} \mathrm{C}\right)$ and less addition of maltodextrin $(100 \%)$ and gum arabic $(10 \%)$. Increasing drying surface temperature provided higher amount of total phenolic content due to the synthesis of polyphenols occur at high temperature, while the increase in maltodextrin and gum arabic decrease the total phenolic content of the dried gac powder.

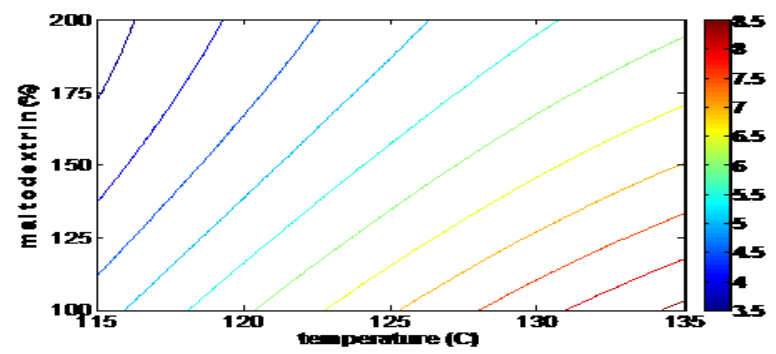

Fig. 4 . The contour plot of total phenolic content of gac powder as affected by drying temperature and maltodextrin content at $10 \%$ gum Arabic

\subsection{Lycopene content}

Fig 5. shows the variation of drying temperature and maltodextrin content at $10 \%$ of gum arabic. It can be seen that drum surface drying temperature has a positive effect on lycopene content, while the addition of maltodextrin results in decreasing lycopene content in gac powder. The maximum lycopene content was $0.18 \mathrm{mg} / 100 \mathrm{~g}$ and occurred at high drying temperature $\left(135^{\circ} \mathrm{C}\right)$ with less addition of maltodextrin $(100 \%)$ due to heat induces isomerization of the all-trans to cis forms which increase with temperature. While the addition of gum arabic had little positive effect on lycopene content.

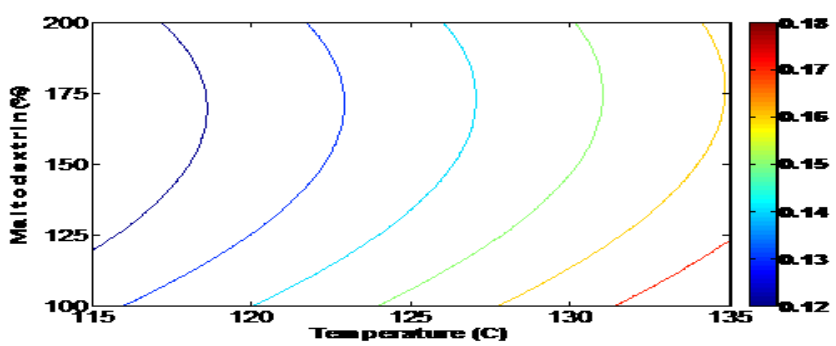

Fig. 5. The contour plot of lycopene content of gac powder as affected by drying temperature and maltodextrin content at $10 \%$ of gum arabic

\subsection{Optimization of drum drying processing parameter to produce gac fruit powder}

Optimization of process conditions for drum drying of gac fruits was done by using response surface methodology and superimposed of contour plots of response variables at different processing conditions. The decision criteria of drum dried gac powder properties consist of moisture content $<5 \%$, Solubility $>70 \%$, Hygroscopicity $<15$ $\mathrm{g}_{\text {water }} / 100 \mathrm{~g}_{\text {powder, }}$, total phenolic content $>6.5 \mathrm{mg} / \mathrm{g}$ and lycopene content $>0.15 \mathrm{mg} / 100 \mathrm{~g}_{\text {powder. }}$ Fig. 6 shows the graphical optimization. It was found that the optimum condition was at $135^{\circ} \mathrm{C}$ drying temperature, maltodextrin and gum arabic at $138 \%$ and $10 \%$ respectively. Physicochemical properties of gac powder composed with $1.48 \%$ of moisture content, $73.91 \%$ of solubility, $14.99 \mathrm{~g}$ $/ 100 \mathrm{~g}$ of hygroscopicity, $7.35 \mathrm{mg} / \mathrm{g}$ of phenolic content and $0.16 \mathrm{mg} / 100 \mathrm{~g}$ of lycopene content.

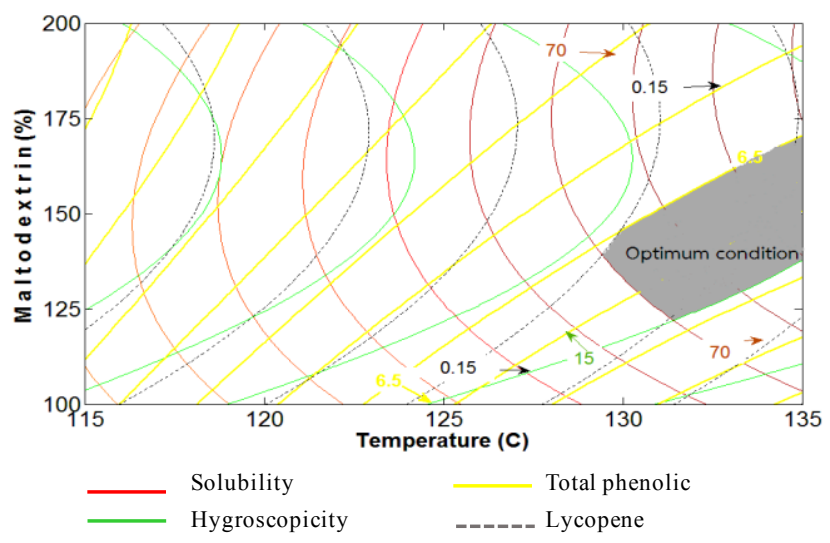

Fig. 6. Superimposed contour plot of response variables.

\section{Conclusion}

Drum drying was used for gac fruit powder production. Response surface optimization was carried out to determine the optimum processing condition of drum surface drying temperature, maltodextrin content and gum arabic content, that provide the desired properties of dried gac powder. The second order polynomial models were successfully developed to describe the response variables at different processing condition.

\section{References}

1. T.C. Kha, M. H. Nguyen, P.D. Roach, S.E. Parks, C. Stathopoulos, Food Reviews International, 29(1), 92-106 (2013)

2. J. Kubola, S. Siriamornpun, Food Chemistry, Volume 127 (3), 1138-1145 (2011)

3. A,S, Mujumdar, Handbook of Industrial Dry ing, CRC Press, Taylor \& Francis Group (2014)

4. P. Galaz, M. Valdenegro, C. Ramírez, H. Nuñez, S. Almonacid, R. Simpson, Food Engineering, 208, 19-27 (2017)

5. B. Adhikari, T. Howes, D. Lecomte, B.R. Bhandari, Powder Technology, 149 (2-3), 168-179 (2005)

6. D. P. S. Oberoi, D. S. Sogi, Food Engineering, 165, 172-178 (2015)

7. C. Agustina, D. Battista, D. Constenla, M. V. Ramírez-Rigo, J.Piña., Powder Technology, 286, 193-201, (2015)

8. I. Atalar, M. Dervisoglu, LWT - Food Science and Technology, 60 (2), 751-757, (2015)

9. S. Vidović, J.Z.Vladić, Ž.G. Vaštag, Z.P. Zeković, L.M. Popović, Powder Technology, 258, 209-215 (2014)

10. S.N Bhusari, K. Muzaffar, P. Kumar, Powder Technology, 266, 354-364 (2014)

11. J.Yang, R.Gadi, R. Paulino, T.Thomson, Food Chemistry, 122(3), 627-632 (2010)

12. M. Nagata, I. Yamashita, J. Japan. Soc. Food sci. Technol, 39(10), 925-928 (1992)

\footnotetext{
* Corresponding author: maradee.ph@kmitl.ac.th
} 